\title{
TRADE AND THE DISTRIBUTION OF HUMAN CAPITAL
}

\author{
SPIROS BOUGHEAS \\ RAYMOND RIEZMAN
}

CESIFO WORKING PAPER NO. 1475

CATEgORY 7: TRADE POLICY

JUNE 2005

\footnotetext{
An electronic version of the paper may be downloaded

- from the SSRN website:

www.SSRN.com

- from the CESifo website:

www.CESifo.de
} 


\title{
TRADE AND THE DISTRIBUTION OF HUMAN CAPITAL
}

\begin{abstract}
We develop a two-country, two-sector model of trade where the only difference between the two countries is their distribution of human capital endowments. We show that even if the two countries have identical aggregate human capital endowments the pattern of trade depends on the properties of the two human capital distributions. We also show that the two distributions of endowments also completely determine the effects of trade on income inequality. Then, we prove that there are long-term gains from trade if the marginal utility of income is constant or as long as losers from trade are compensated by winners. Finally, we look at a simple majority voting model. It turns out depending on the distribution of human capital, autarky and free trade with and without compensation may be the outcome of majority voting.
\end{abstract}

JEL Code: F1.

Keywords: patterns of trade, income distribution, welfare, political economy.

Spiros Bougheas

Room B41, Economics \& Geography Bldg.

University of Nottingham

University Park

Nottingham NG7 2RD

United Kingdom

spiros.bougheas@nottingham.ac.uk
Raymond Riezman

University of Iowa

Department of Economics

W360 PBB

Iowa City, IA 52242

USA

raymond-riezman@uiowa.edu

We would like to thank Rick Bond, Indraneel Dasgupta, Carl Davidson, Rod Falvey, Udo Kreickemeier, Steve Matusz, Doug Nelson, seminar participants at the Midwest International Economics Group meeting, the Kobe COE Conference on International Trade, the COE/RES Workshop on International Trade and Investment at Hitotsubashi University, Michigan State University and the University of Nottingham for helpful comments. Financial support from the Leverhulme Trust (Programme Grant F114/BF) is gratefully acknowledged. 


\section{Introduction}

In recent years the impact of trade on income inequality has been a topic widely discussed in both academic and policy forums. What has triggered interest in this topic is a growing concern among industrialized nations about their ability to sustain high standards of wellbeing in the face of competition from low wage countries. Naturally, at the theoretical level these issues have been addressed within models where trade is motivated because of differences in technologies and aggregate endowments. ${ }^{1}$ However, it has also been noticed that a large volume of international trade takes place between countries with similar technologies and aggregate endowments and work in this area has focused in explaining their patterns of trade. ${ }^{2}$

In this paper, we argue that the implications for inequality and welfare of this second type of trade have not been fully explored. It is well understood that trade produces both winners and losers. It is also well understood that if it is accompanied by an appropriate compensation scheme it will Pareto-dominate autarky. However, it is not clear at all whether, in models with agent heterogeneity, there exist socially acceptable mechanisms that can implement such Pareto optimal outcomes. For example, when both the trade regime and any redistribution schemes are decided by a majority rule.

In order to address these issues we develop a two-country, two-sector model of trade where the only difference between the two countries is in their distribution of human capital endowments. Their technological capabilities and the preferences of their consumers are identical. In each country there is a primary sector where output is produced using labor and a high-tech sector that uses human capital as its input. We will demonstrate that even if the two countries have identical aggregate human capital endowments they will trade with the patterns of trade depending on the properties of the two human capital distributions. In fact, in our framework differences in size do not affect the patterns of trade. Knowledge of the two human capital distributions is alone sufficient. ${ }^{3}$

\footnotetext{
${ }^{1}$ Both the theoretical and empirical literatures are extensive and have recently been reviewed by Feenstra and Hanson (2001).

${ }^{2}$ See Brander (1991), Davis (1995), Grossman and Maggi (2000) and Krugman (1979) for theoretical attemts to account for this observation.

${ }^{3}$ To our knowledge, Ishikawa (1996) was the first to explore the relationship between the distribution of human capital and the patterns of trade. However, he has restricted his attention to countries that differ in aggregate endowments while we are also interested in differences in the variance of the two distributions.

Grossman and Maggi (2000) using production technologies where workers' talents can be complementary in some sectors and substitutable in others have also found that the
} 
We will also show that together the two distributions of endowments also completely determine the effects of trade on income inequality. More specifically, we will find that the latter always rises in the country that exports the high-tech product and declines in the country that exports the primary commodity. However, knowledge of endowment distributions alone is not sufficient for drawing general conclusions about the impact of trade on the world income distribution.

Next, we explore the welfare implications of our model. Not surprisingly, we prove that there are long-term gains from trade as long as losers are compensated. ${ }^{4}$ However, designing and introducing appropriate compensation schemes can both be problematic. Design problems arise because of the difficulty not only of separating those who gain from those who lose but also assessing the exact size of the corresponding gains and losses. But even in the absence of design problems compensation schemes might not be introduced because in models with agent heterogeneity compensation might not be the outcome preferred by the majority. ${ }^{5}$ With these observations in mind, we compare total welfare under autarky with the corresponding welfare under trade and find that, unless the marginal utility of income is constant, there exist free-trade equilibria that are welfare reducing.

Then it is natural to ask what is the relationship between the initial distribution of endowments and aggregate welfare assuming that the issues of openness and compensation are decided by a majority vote. We provide a complete characterization of politico-economic outcomes and find that there exist equilibria that do not enhance welfare. This happens either because the majority decides that the country should not trade or that it should trade but not provide any compensation for losers from trade.

distribution of human capital can potentially matter for a country's patterns of trade. This is in contrast with our paper where as long as the distributions differ the two countries can benefit from trade.

In addition, both of the above paper focus on trade patterns while we are also interested on trade's consequences for inequality and welfare.

Lastly, distributions also matter in Grossman (2004) but in his model firms are not perfectly informed about workers' productivity and their output is not verifiable by their employees.

\footnotetext{
${ }^{4}$ Here, we completely ignore any short-term adjustment costs as the economy moves from one regime to another. See Davidson and Matusz $(2002,2004)$ for interesting work in this area.

${ }^{5}$ See Davidson, Matusz and Nelson (2004) for an in-depth analysis of these issues within a framework similar to ours.
} 


\section{The Model}

There are two countries: $A$ and $B$. Each country is populated by a continuum of agents of measure 1. Each agent ( $i$ for country $A$ and $j$ for country $B$ ) is endowed with one unit of labor and some level of human capital, $h_{i}\left(h_{j}\right)$, randomly drawn from the interval $\left[1, h_{M A X}\right]$. Let $f_{A}$ and $f_{B}$ denote the density functions and $F_{A}$ and $F_{B}$ the corresponding human capital distribution functions of countries $A$ and $B$ respectively.

There are two goods $X$ and $Y$. Good $Y$ is a primary commodity and each unit produced requires one unit of labor. In contrast, good $X$ is a high-tech product and each unit produced requires, in addition, one unit of human capital. The amount of good $X$ produced by an agent corresponds to their level of human capital. So, an agent with human capital $h_{i}$ produces $h_{i}$ units of good $X$.

All agents derive utility from the consumption of both goods and they have identical homothetic preferences.

\subsection{Autarky}

In this section, we derive the equilibrium under autarky. Without any loss of generality we concentrate on country $A$.

\subsubsection{Production Possibilities Frontier}

The maximum amount of good $Y$ that can be produced is equal to 1. Each agent uses her single labor unit endowment to produce one unit of the primary good. The slope of the PPF at the point where it intersects the $x$ axis is equal to $-\left(1 / h_{M A X}\right)$. This is because efficiency requires specialization according to comparative advantage, and the agent with the most comparative advantage in producing $X$ is agent $h_{M A X}$. However, as production of the high-tech product increases the PPF gets steeper because the new producers have lower human capital endowments. The maximum amount of good $X$ that the economy can produce, $\hat{h}_{A}$ is attained when all the agents produce good $X$, hence, is equal to the average endowment of human capital. That is,

$$
\hat{h}_{A}=\int_{1}^{h_{M A X}} h_{i} f_{A}(h) d h
$$

At the point where the PPF crosses the $y$ axis its slope is equal to -1 . In general, the marginal rate of transformation (the absolute value of the slope) 


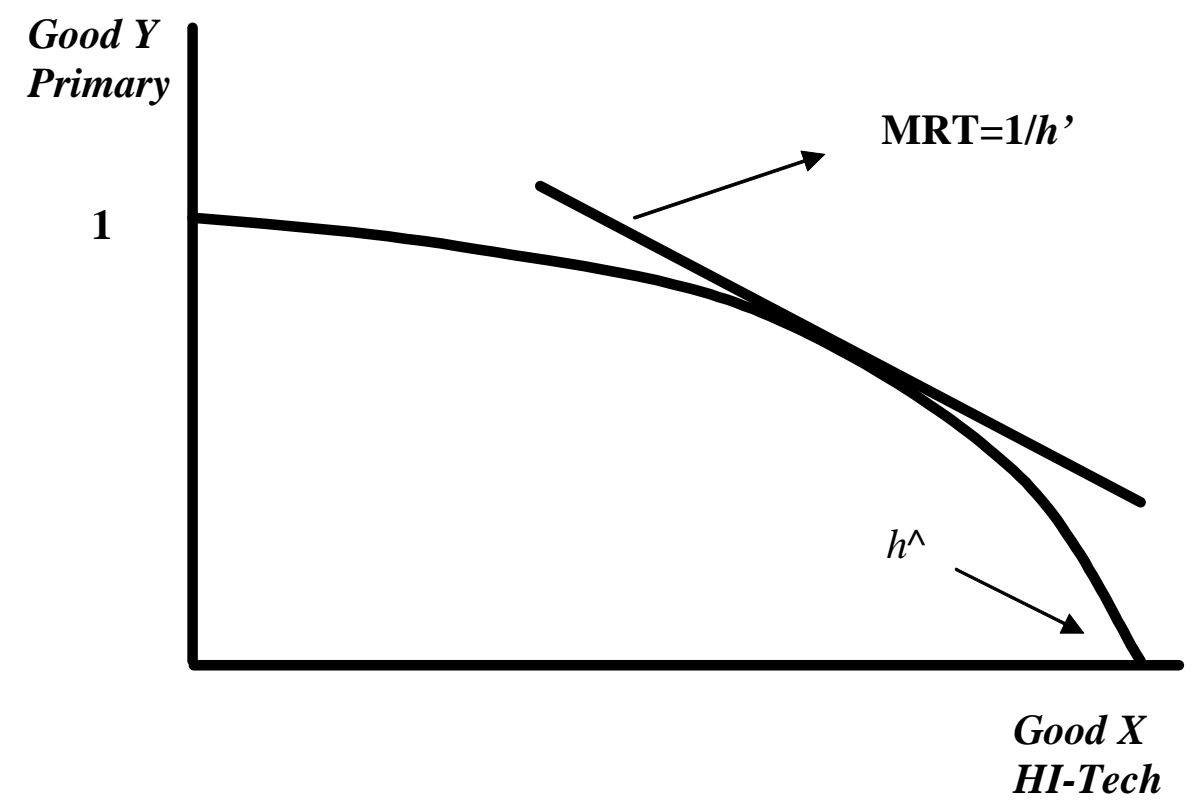

Figure 1: Production Possibilities Frontier

is equal to $1 / h^{\prime}$ where $h^{\prime}$ is equal to the human capital endowment of the agent with the highest endowment among those producing good $Y$. Figure 1 shows the graph of the PPF.

\subsubsection{Equilibrium}

Define as $p_{A}$ the relative price (i.e. the price of good $Y$ measured in units of good $X), q_{A}(X)$ the quantity produced of good $X$ and $q_{A}(Y)$ the corresponding quantity of good $Y$. Then,

Proposition 1 Equilibrium under Autarky:

The equilibrium price satisfies $1<p_{A}<h_{M A X}$ and there exists a critical level of human capital endowment, $h_{A}^{*}$, such that $p_{A}=h_{A}^{*}$, all agents with $h_{i}<h_{A}^{*}$ produce good $Y$, all agents with $h_{i}>h_{A}^{*}$ produce good $X, q_{A}(Y)=$ $\int_{1}^{h_{A}^{*}} f_{A}(h) d h$, and $q_{A}(X)=\int_{h_{A}^{*}}^{h_{M A X}} h f_{A}(h) d h$. 
Proof. The proposition follows from straightforward arbitrage arguments.

Notice that agents with human capital endowments equal to $h_{A}^{*}$ are indifferent between producing $X$ or $Y$.

\subsubsection{Income Distribution}

In order to measure incomes we need a numeraire. Any welfare comparisons before and after a change in relative prices will be affected by the choice of numeraire. However, as long as we are interested in changes in inequality the choice of numeraire is inconsequential. With this in mind we use good $X$ as the numeraire. Then, for each type of equilibrium we can derive the corresponding income distribution of the economy. Let $z_{i}$ denote the income of agent $i$. Then,

Proposition 2 Income Distribution under Autarky:

Under Autarky, $z_{i}=h_{A}^{*}$ for all $i$ such that $h_{i} \leqslant h_{A}^{*}$, and $z_{i}=h_{i}>h_{A}^{*}$ for all $i$ such that $h_{i}>h_{A}^{*}$. The proportion of agents with income exactly equal to $h_{A}^{*}$ is given by $F_{A}\left(h_{A}^{*}\right)$ and the proportion of agents with income higher than $h_{A}^{*}\left(h_{A}^{*}<h_{i}<h_{M A X}\right)$ is given by $1-F_{A}\left(h_{A}^{*}\right)$.

We next illustrate what autarky equilibrium looks like for a particular utility function.

Example 1 Suppose that preferences are described by the utility function: $U(X, Y)=U(X, Y)=A X^{\gamma} Y^{\delta}$. For a given price $p_{A}$, those agents with $h_{i} \geqslant p_{A}$ (producers of $X$ ) maximize the above utility subject to the budget constraint: $h_{i}-X-p_{A} Y=0$ that yields the following demand functions:

$$
X=h_{i} \frac{\gamma}{\gamma+\delta}, \quad Y=\frac{h_{i}}{p_{A}} \frac{\delta}{\gamma+\delta}
$$

while those agents with $h_{i} \leqslant p_{A}$ (producers of $Y$ ) maximize the same utility subject to the budget constraint: $p_{A}-X-p_{A} Y=0$ that yields the demand functions:

$$
X=p_{A} \frac{\gamma}{\gamma+\delta}, \quad Y=\frac{\delta}{\gamma+\delta}
$$

The equilibrium price $h_{A}^{*}$ is such that the supply of $Y$ (demand for $X$ ) is equal to the demand for $Y$ (supply of $X$ ); in other words it satisfies the following equality:

$$
\int_{1}^{h_{A}^{*}} \frac{\gamma}{\gamma+\delta} f_{A}(h) d h=\int_{h_{A}^{*}}^{h_{M A X}} \frac{h_{i}}{h_{A}^{*}} \frac{\delta}{\gamma+\delta} f_{A}(h) d h
$$


Notice that each producer of $Y$ produces 1 unit, consumes $\frac{\delta}{\gamma+\delta}$ units and supplies $\frac{\gamma}{\gamma+\delta}$ units of $Y$. Simplifying the above expression we get:

$$
p_{A}=h_{A}^{*}=\frac{\delta}{\gamma} \frac{\int_{h_{A}^{*}}^{h_{M A X}} h_{i} f_{A}(h) d h}{F_{A}\left(h_{A}^{*}\right)}=\frac{\delta}{\gamma} \frac{q_{A}(X)}{q_{A}(Y)}
$$

\section{$2.2 \quad$ Free Trade}

We next turn to consideration of opening up to international trade. In our two country model the only way that the two countries differ is in their distributions of human capital endowments. In general, this implies that $p_{A} \neq p_{B}\left(h_{A}^{*} \neq h_{B}^{*}\right)$ which means that autarky prices differ in the two countries. Different relative autarky prices imply that there are opportunities for trade. Thus, countries with identical amounts of human capital but different distributions of human capital will still have an incentive to trade.

\subsubsection{Free Trade Equilibrium}

As is usually the case, the autarky prices will determine the pattern of international trade.

Proposition 3 The country with the higher relative autarky price ratio will export good $X$ and import good $Y$.

Proof. Without loss of generality, consider the case where $p_{A}>p_{B}\left(h_{A}^{*}>\right.$ $\left.h_{B}^{*}\right)$. Consider an agent in country $A$ with endowment $h_{A}^{*}-\varepsilon(\varepsilon>0$ and small). Under autarky, that agent produces one unit of $Y$ and consumes any linear combination of one unit of $Y$ and $h_{A}^{*}$ units of $X$. When trade is allowed that same agent will produce $h_{A}^{*}-\varepsilon$ units of $X$, and trade them for $\left(h_{A}^{*}-\varepsilon\right) \frac{1}{p_{B}}>1$ units of $Y$ and consumes any linear combination of $\left(h_{A}^{*}-\varepsilon\right) \frac{1}{p_{B}}>1$ units of $Y$ and $\left(h_{A}^{*}-\varepsilon\right) p_{A} / p_{B}=\left(h_{A}^{*}-\varepsilon\right) \frac{1}{p_{B}} h_{A}^{*}>h_{A}^{*}$ units of $X$. A similar argument shows that an agent in country $B$ with endowment $h_{B}^{*}+\varepsilon$ who produced good $X$ under autarky produces good $Y$ under free trade. At the global equilibrium there is a cut-off level of human capital endowment, $h_{G}^{*}\left(h_{B}^{*}<h_{G}^{*}<h_{A}^{*}\right)$, such that all agents in both countries with endowments higher than $h_{G}^{*}$ produce good $X$ and all agents with endowments less than $h_{G}^{*}$ produce good $Y$. This means that more $X$ is produced in country $A$ and less $X$ is produced in country $B$ implying that country $A$ will export good $X$.

In order to calculate the free-trade price we need to construct the global PPF. 


\subsubsection{Global PPF}

Using each country's human capital endowments and their identical technologies we can construct a global PPF. The construction of the global frontier follows the same rules as those followed for the construction of each individual frontier using the global distribution of human capital endowments. The latter distribution denoted by $G$ is given by:

$$
G(h)=\frac{F_{A}(h)+F_{B}(h)}{2}
$$

The maximum quantity of $Y$ that the two countries can produce is equal to 2 and the corresponding quantity of $\operatorname{good} X$ is equal to $\hat{h}_{A}+\hat{h}_{B}$.

We use the same utility function of Example 1 and compute the free trade price.

Example 2 Suppose that preferences are described by the utility function: $U(X, Y)=A X^{\gamma} Y^{\delta}$. The free trade price, $p_{T}$, is equal to $h_{G}^{*}$ and is given by:

$$
p_{T}=h_{G}^{*}=\frac{\delta}{\gamma} \frac{\int_{h_{G}^{*}}^{h_{M A X}} h_{i} g(h) d h}{G\left(h_{G}^{*}\right)}
$$

where $g$ is the density of $G$.

\subsubsection{The Effect of Country Size}

To this point, we have assumed that the two countries are of equal size. However, in our model it is simple to derive the global trade equilibrium when the sizes of the two countries are not equal. In this section, we change the population of country $B$ so that it is $n$ times larger than country $A$. The human capital distributions are assumed to be the same as above. This implies that the measure of country $B$ 's distribution is equal to $n$. Notice, as there are not any economies of scale in our model, that this change has no effect on country $B$ 's autarky price. It is as if $n$ countries with exactly the same human capital distribution and of equal size attempt to trade. However, there are not any gains from trade because all of them have the same autarky price.

Our analysis in the previous section suggests that in order to find the new global trade equilibrium price we need to derive the global human capital distribution. We denote this new distribution by $G^{n}(h)$ and is given by:

$$
G^{n}(h)=\frac{F_{A}(h)+n F_{B}(h)}{n+1}
$$


Lemma 1 As $n \longrightarrow \infty, G^{n}(h) \longrightarrow F_{B}(h)$.

The above lemma states that as the difference in size gets larger the global trade equilibrium price approaches the autarky price of the larger country. In the limit, the small country cannot influence the global trade equilibrium price. ${ }^{6}$

\subsubsection{Patterns of Trade}

Suppose that the two countries are of equal size and their human capital distributions have the same mean which implies that their aggregate endowments are equal. If the two human capital distributions are different then the autarky prices will be different. This implies that aggregate endowments may not be accurate predictors of the patterns of trade. This leads to two questions.

The first is under what conditions will a country that has a higher aggregate endowment in human capital export the human capital intensive good? The second question is what properties of human capital distributions provide reliable guides to predict trade patterns? We answer the first question with the following proposition.

Proposition 4 Suppose that preferences are Cobb-Douglas the sizes of the two countries are equal and let $F_{B}(h)$ dominate $F_{A}(h)$ in the sense of firstorder stochastic dominance. Then country $B$, that is the human capital abundant country, will export the human capital intensive good.

Proof. We need to show that $h_{A}^{*}<h_{B}^{*}$. First-order stochastic dominance implies that $F_{A}(h) \geqslant F_{B}(h)$ and $\int_{h^{\prime}}^{h_{M A X}} h_{i} f_{A}(h) d h<\int_{h^{\prime}}^{h_{M A X}} h_{i} f_{B}(h) d h$ for every $h^{\prime}$. Then the inequality follows directly from the autarky price equilibrium condition (1).

This proposition identifies the patterns of trade for the case in which one human capital distribution dominates the other in the sense of first-order stochastic dominance. In this case the variances of the two distributions do not matter. Hence, the pattern of trade depends only on aggregate endowments as in the Heckscher-Ohlin-Samuelson model. Figure 2 illustrates the above result.

\footnotetext{
${ }^{6}$ In our model, as long as two countries have identical human capital distributions, even if they differ in size, they will not trade because their autarky prices are the same. In contrast, in Ishikawa (1996) national economies of scale with respect to human capital lead to different autarky prices and thus to trade.
} 


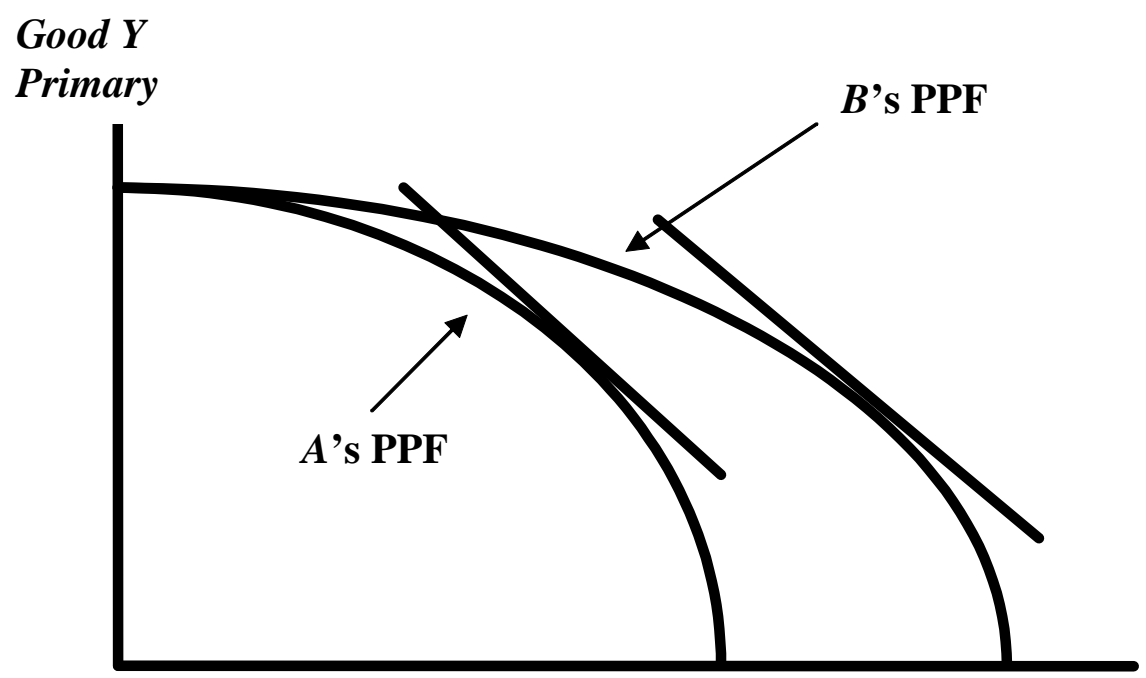

Good X

HI-Tech

Figure 2: Comparative Advantage under First-Order Stochastic Dominance 
Given that the populations of the two countries are equal both production possibilities frontiers intersect the $y$ axis at the same point. However, if the two countries produce only the high-tech good then country $B$, that is the country with the higher endowment, will produce more. What the proposition demonstrates is that when the two production possibilities frontiers have the same slope then $\frac{q_{A}(Y)}{q_{A}(X)}>\frac{q_{B}(Y)}{q_{B}(X)}$. Thus, given homothetic preferences, country $B$ exports the high-tech good.

The above result contrasts with the no-trade result that Grossman and Maggi (2000) derive under first-order stochastic dominance. In their model, both sectors exhibit constant returns to scale in talent (our human capital) and thus the slopes of the two PPFs at points where any ray through the origin crosses them are equal. Then homotheticity implies that under autarky the two countries produce exactly the same ratio of quantities of the two goods and thus there is no comparative advantage and hence, no trade. In contrast, in our model the returns to human capital vary across sectors and thus, there are gains from trading.

To provide an answer to the second question we consider the case of two distributions of human capital that have the same mean but different variance (mean-preserving spreads) with the additional restriction that their cumulative distribution functions cross only once. Let the variance of country $A$ 's distribution be higher than that of country $B$ 's. In the terminology of Grossman and Maggi (2000) the country A's distribution is more diverse than country $B$ 's. Figure 3 shows the two production possibilities frontiers.

Notice that the two PPFs share the same intercepts. This is because (a) the populations of the two countries are equal that implies that the maximum amount of good $Y$ that they can produce is the same, and (b) aggregate endowments are the same which implies that the maximum amount of good $X$ that they can produce is also the same. Notice that country $B$ 's PPF lies inside country $A$ 's PPF. This follows from the fact that if $F_{A}(h)$ is more diverse than $F_{B}(h)$ then $\int_{h^{\prime}}^{h_{M A X}} h f_{A}(h) d h>\int_{h^{\prime}}^{h_{M A X}} h f_{B}(h) d h$. That is, if the two countries produce both goods and also produce the same quantity of $Y$ then country $A$ will produce a higher quantity of $X$.

The implications for the trade pattern are clear. First note that in the vicinity of the $y$ intercept country $A$ 's PPF is flatter than $B$ 's while it is steeper in the vicinity of the $x$ intercept. Then, continuity implies that there exists a unique ray through the origin $\left(\frac{q_{A}\left(Y^{*}\right)}{q_{A}\left(X^{*}\right)}=\frac{q_{B}\left(Y^{*}\right)}{q_{B}\left(X^{*}\right)}\right)$ such that at the points where it crosses the two PPFs their slopes are equal $\left(M R T_{A}=\right.$ $\left.M R T_{B}=M R T^{*}\right)$. If we are to the left of that ray, i.e. $M R S<M R T^{*}$, then $\frac{q_{A}(Y)}{q_{A}(X)}<\frac{q_{B}(Y)}{q_{B}(X)}$ meaning that Country $A$ exports $X$, the high-tech good. If 


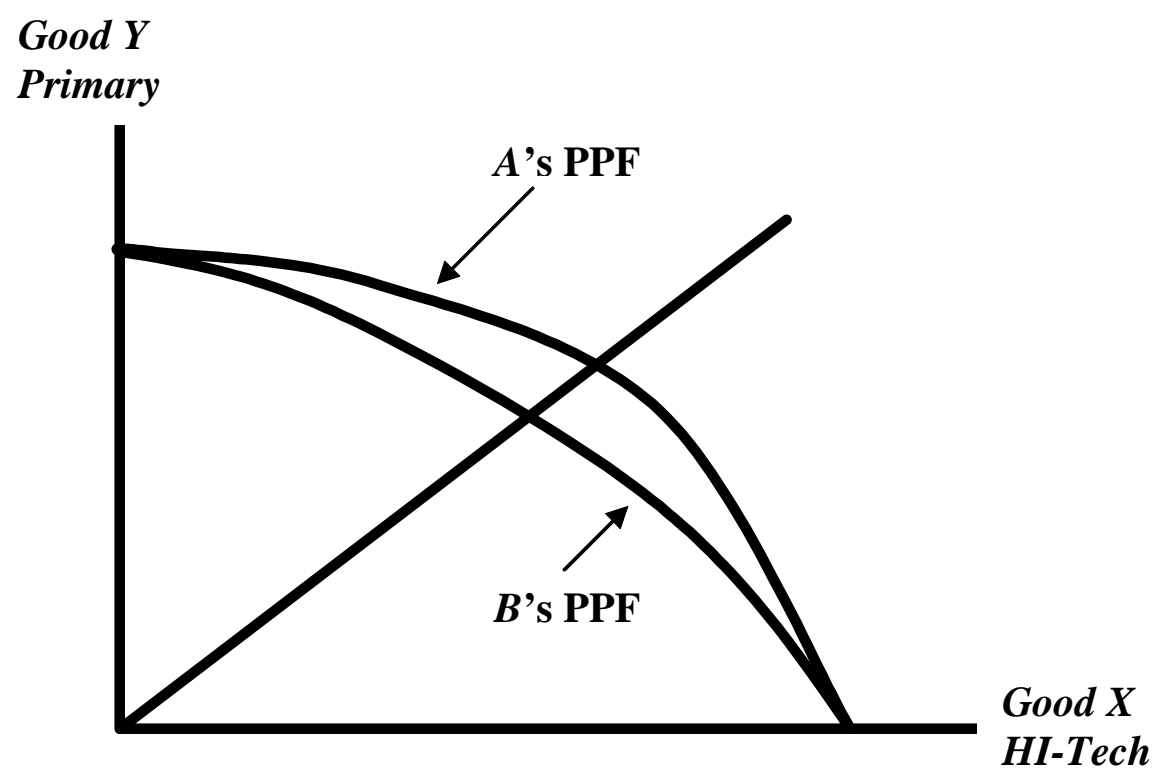

Figure 3: Comparative Advantage under Mean-Preserving Spreads 
we are to the right of that ray, i.e. $M R S>M R T^{*}$, then $\frac{q_{A}(Y)}{q_{A}(X)}>\frac{q_{B}(Y)}{q_{B}(X)}$ and country B exports the high-tech good.

One implication of the above discussion is that when countries only differ in the distributions of their endowments, these distributions alone are not sufficient to determine the pattern of trade. We also need to know the exact specification of preferences even when they are the same for all agents. Once more, this result contrasts with the corresponding result in Grossman and Maggi (2000). In their model the more diverse country always exports the good that is produced using a process characterized by input substitutability while the less diverse country exports the good that is produced using a process characterized by input complementarity. Therefore, the two distributions completely determine the pattern of trade. The following proposition summarizes our results for the case of uniformly distributed endowments.

Proposition 5 Suppose that the preferences of agents are described by the utility function $U(X, Y)=A X^{\gamma} Y^{\delta}$ (let $\left.k \equiv \frac{\delta}{\gamma}\right)$, the sizes of the two countries are equal, the endowments of country $A$ are uniformly distributed on $[1,2]$ and those of country $B$ are uniformly distributed on $[1+x, 2-x]$; where $(0<x<0.5)$. Then for each $x$ there exists a $k^{*}$ such that for every $k<k^{*}$ country $B$ will export the human capital intensive good while for every $k>k^{*}$ country A will export the human capital intensive good.

Proof. Notice that $f_{A}=1, F_{A}=h-1, f_{B}=\frac{1}{1-2 x}$ and $F_{B}=\frac{h-1-x}{1-2 x}$. Then substituting these expressions in (1) we can solve for the two autarky prices:

$$
p_{A}=h_{A}^{*}=\frac{1+\sqrt{1+4(1+0.5 k) 2 k}}{2+k}
$$

and

$$
p_{B}=h_{B}^{*}=\frac{1+x+\sqrt{(1+x)^{2}+4(1+0.5 k)\left(2(1-x)+0.5 x^{2}\right) k}}{2+k}
$$

We observe that, since $x<0.5$, both prices are monotonically increasing in $k$ and that $\lim _{k \rightarrow 0} \frac{h_{A}^{*}}{h_{B}^{*}}<1$ and $\lim _{k \rightarrow \infty} \frac{h_{A}^{*}}{h_{B}^{*}}>1$. These conditions are sufficient for the existence of $k^{*}$ which completes the proof of the proposition.

Above we consider two countries with identical aggregate endowments and preferences. However, country $A$ 's distribution of human capital endowments has a higher variance than country $B$ 's corresponding distribution. The production possibilities frontiers of the two countries are depicted graphically in figure 3. At the point where the PPFs cross the horizontal 
axis the PPF of country $A$ has a slope equal to 2 while the one of country $B$ 's has a slope equal to $2-x$. In contrast, at the point where the PPFs cross the vertical axis the PPF of country $A$ has a slope equal to 1 while the one of country $B$ 's has a slope equal to $1+x$.

What happens to the patterns of trade depends on the relative preferences for each good and on the tails of the two distributions. As an extreme example, consider the case where there is a very strong preference for the human capital intensive good. Then the primary good will only be produced in country $A$ by those agents with very low endowments of human capital. Similarly, if there is a very strong demand for the primary commodity then the human capital intensive good will once more only be produced in country $A$ but now by those agents on the upper tail of the distribution.

Example 3 Consider an example based on the above proposition. Let $x=$ 0.2 . Then $k^{*}=1.55$ and for that value the autarky price in both countries is the same and equal to 1.612 . For $k<1.55$ country $B$ will export the high-tech product while for $k>1.55$ country $A$ will export it.

The analysis of the patterns of trade so far was restricted to the case of countries of equal size. It turns out that this restriction is inconsequential because size variations do not affect the patterns of trade. The results of section 2.2.3 suggests that the patterns of trade are completely determined by differences in autarky prices which in turn are completely determined by the distributions of human capital endowments. Put differently, two countries that are not of equal size but have the same human capital distribution will also have the same autarky prices.

\subsubsection{Trade and Inequality}

We compare the income distributions of each country under autarky and after trade. In this section, we are only interested in changes in inequality and thus the choice of numeraire does not matter. We begin with the following lemma.

Lemma 2 Trade increases inequality in the country that exports the hightech product and reduces inequality in the country that exports the primary commodity.

Proof. Without any loss of generality, assume that $h_{B}^{*}<h_{G}^{*}<h_{A}^{*}$. therefore at the global equilibrium country $A$ exports the high-tech product while country $B$ exports the primary commodity. Using again good $X$ as 
the numeraire, we observe that, after trade, country $A$ 's income distribution is as follows: $z_{i}=h_{G}^{*}$ for all $i$ such that $h_{i} \leqslant h_{G}^{*}$, and $z_{i}=h_{i}>h_{G}^{*}$ for all $i$ such that $h_{i}>h_{G}^{*}$. Comparing this distribution to the corresponding one obtained under autarky we find that all agents with $h_{i} \leqslant h_{G}^{*}$ (proportion equal to $\left.F_{A}\left(h_{G}^{*}\right)\right)$ have experienced a decrease in income equal to $h_{A}^{*}-h_{G}^{*}$, those agents with $h_{G}^{*}<h_{i}<h_{A}^{*}$ (proportion equal to $F_{A}\left(h_{A}^{*}\right)-F_{A}\left(h_{G}^{*}\right)$ ) have experienced a decrease in income equal to $h_{A}^{*}-h_{i}$, while the income of the rest of the agents (proportion equal to $1-F_{A}\left(h_{A}^{*}\right)$ ) has remained the same. Therefore, the poor have experienced the greatest relative loss in income, the loss of the middle-income group has been more moderate, while the incomes of those agents in the high-income group has remained unchanged. Similarly, comparing country $B$ 's after trade income distribution to the corresponding one obtained under autarky we find that the income of the poor (proportion equal to $\left.F_{B}\left(h_{B}^{*}\right)\right)$ has increased by $h_{G}^{*}-h_{B}^{*}$, the income of those in the middle income group (proportion equal to $F_{B}\left(h_{G}^{*}\right)-F_{B}\left(h_{B}^{*}\right)$ ) has increased by $h_{G}^{*}-h_{i}$, while the incomes of those agents in the high-income group (proportion equal to $1-F_{B}\left(h_{G}^{*}\right)$ ) has remained unchanged. ${ }^{7}$

We can now prove the main result of this section.

Proposition 6 Part1: Suppose that country B's distribution dominates country $A$ 's distribution in the sense of first-order stochastic dominance. Then trade will increase inequality in country $B$ and decrease inequality in country A.

Part 2: Suppose that countries $A$ and $B$ have the same aggregate endowments but country $A$ 's distribution is more diverse than country $B$ 's. Then trade will increase inequality in country $A$ if there is relatively strong demand for the primary good while inequality in country $B$ will increase if there is relatively strong demand for the high-tech good.

Proof. The proof of part 1 follows from Proposition 4 and Lemma 2 and that of part 2 (for the case of uniform distributions) follows from Proposition 5 and Lemma 2.

The above results suggest that trade has the opposite effect on the income inequality of the two trading partners. In contrast, Feenstra and Hanson

\footnotetext{
${ }^{7}$ In general, we need to be cautious with inequality comparisons because one needs to take into account not only relative income changes but also absolute ones. For example, an increase in the gap between rich and poor does not necessarily imply an increase in inequality if it is also accompanied by an increase in per capita income that is uniformly distributed. Nevertheless, such concerns are clearly irrelevant for our model. When inequality increases, depending on the numeraire used either the rich get richer and the poor stay the same or the poor get poorer and the rich stay the same.
} 
(1996) and Zhu and Trefler (2005) find that inequality increases in both countries. The difference is that they focus on trade between developed and developing nations where trade is driven by differences in technology whereas we are interested in trade between countries with similar technologies, but different distributions of human capital.

Trade and human capital unemployment Here, as in the HeckscherOhlin-Samuelson model, we also find that in the country that imports the human capital intensive good the return to human capital falls and the reverse happens in the country that exports it. However, in our model, in addition to this price effect, we have a quantity effect that works in the same direction. In the Heckscher-Ohlin-Samuelson model there is full employment of all inputs in both countries both before and after trade. In contrast, in our model, human capital is only partially employed. In fact, its employment increases in the country that exports the human capital intensive good while it declines in the other country. Having said that, there are no welfare losses associated with the underemployment of human capital as its employment is chosen optimally. ${ }^{8}$

\subsection{The World Income Distribution}

Before we examine the welfare properties of our economy we compare the pre-trade world income distribution with the corresponding post-trade one. Under the assumption that the populations of the two countries are equal the world income distribution under autarky is given by:

$$
\begin{array}{ll}
\text { Proportion of Agents } & \text { Income } \\
\frac{F_{B}\left(P_{B}\right)}{2} & P_{B} \\
\frac{F_{B}\left(P_{A}\right)-F_{B}\left(P_{B}\right)}{2} & P_{B}<h_{i}<P_{A} \\
\frac{F_{A}\left(P_{A}\right)}{2} & P_{A} \\
1-\frac{F_{B}\left(P_{A}\right)+F_{A}\left(P_{A}\right)}{2} & P_{A}<h_{i}<h_{M A X}
\end{array}
$$

The post trade world income distribution is given by:

$$
\begin{array}{ll}
\text { Proportion of Agents } & \text { Income } \\
\frac{F_{B}\left(P^{*}\right)+F_{A}\left(P^{*}\right)}{2} & P^{*} \\
1-\frac{F_{B}\left(P^{*}\right)+F_{A}\left(P^{*}\right)}{2} & P^{*}<h_{i}<h_{M A X}
\end{array}
$$

\footnotetext{
${ }^{8}$ This need not be the case if we extend the model to allow for endogenous human capital accumulation. If agents, at the time they make their investment decisions, are uncertain about the trade regime then either over-accumulation or under-accumulation of human capital can result.
} 
Comparing the two tables we observe that trade reduces the gap between the rich and the poor and that there is income convergence within sectors. However, without any information about the two human capital distributions we cannot make any general statements about world inequality. In fact, propositions 5 and 6 together suggest that whether the gap between two countries' inequality measures increases or decreases after they trade depends on the patterns of trade which in turn, depend on the two endowment distributions and preferences.

\section{Welfare}

In this section we are going to demonstrate that uncompensated trade does not necessarily enhance social welfare. We know that not all agents gain from trade. But here we are going to prove a stronger result; namely that if the losers are not compensated then trade might reduce social welfare. We measure welfare by using a standard additive social welfare function:

$$
W(h, p)=\int_{1}^{h_{M A X}} U(X(h, p), Y(h, p)) f(h) d h
$$

Let $p^{a}$ denote the equilibrium relative price under autarky. If trade is welfare improving then the following must be true:

$$
p^{a}=\arg \min \left\{\int_{1}^{h_{M A X}} U(X(h, p), Y(h, p)) f(h) d h\right\}
$$

That is, if trade is welfare improving then the social welfare must be minimized when agents trade at autarky prices. We can prove the following result:

Proposition 7 Suppose that the preferences of agents are described by the utility function $U(X, Y)=A X^{\gamma} Y^{\delta}$. Then, unless $\gamma+\delta=1$, there exists a set of prices such that if the country trades at those prices its welfare will decrease.

Proof. See the Appendix.

To understand the intuition for this result consider the postulated 'weighted utilitarian' social welfare function. One can think of this welfare function as representing the expected utility of an agent whose endowment is randomly drawn from a distribution that is the same as the distribution of aggregate endowments. Suppose we change $\gamma$ and $\delta$ but we keep the ratio $\frac{\gamma}{\delta}$ constant. 
We know that such a change will only affect the marginal utility of income leaving equilibrium prices and quantities unaltered. However, expected utility valuations are affected by changes in the marginal utility of income.

We next identify the relationship between the marginal utility of income and the social welfare minimizing prices to better understand the circumstances under which uncompensated trade can reduce social welfare. The next proposition completely characterizes the prices for which social welfare falls. ${ }^{9}$

Proposition 8 Suppose that the preferences of agents are described by the utility function $U(X, Y)=A X^{\gamma} Y^{\delta}$ and that endowments are uniformly distributed on the interval $[1,2]$. If $\gamma+\delta<1$ then there exists an interval $\left(p, p^{a}\right)$ such that if the country trades at a price in that interval its social welfare will be lower relative to autarky. Similarly, if $\gamma+\delta>1$ then there exists an interval $\left(p^{a}, \bar{p}\right)$ such that if the country trades at a price in that interval its social welfare will be lower relative to autarky.

Proof. See the Appendix.

Putting Propositions 7 and 8 together the intuition is straightforward. When $\theta<1$ the marginal utility of income is decreasing in income. We know that when the equilibrium free trade price is below the autarky price inequality increases. What happens in this case is that trade transfers income from the relatively poor to the relatively rich. But, given that agents marginal utility of income is decreasing in income, the absolute value of the welfare losses of the poor are higher than the welfare gains of the rich. In contrast, when $\theta>1$ the marginal utility of income is increasing in income. When the equilibrium free trade price is above the autarky price inequality decreases. In this case, trade transfers income from the relatively rich to the relatively poor. But given that agent's marginal utility of income is increasing the absolute value of the welfare losses of the rich are higher than the welfare gains of the poor.

Example 4 Suppose that the preferences of agents and their endowment distribution have the same specifications as those used in the above proposition. Using the equilibrium condition under autarky given by equation (1), we find that $p^{a}=1.53518$. We will consider two cases. Case (1): $\gamma=\delta=0.1$ (decreasing marginal utility of income). The social welfare

\footnotetext{
${ }^{9}$ It will become clear that the result must hold for any atomless distribution with a convex domain. However, our method of proof cannot be applied for general specifications of distribution functions.
} 
under autarky is equal to 1.05744. The price that minimizes social welfare is equal to 1.50743, the corresponding social welfare is equal to 1.05738 and $p=1.47985$. Case (2): $\gamma=\delta=0.9$ (increasing marginal utility of income). $\bar{T}$ The social welfare under autarky is equal to 1.67189 . The price that minimizes social welfare is equal to 1.55999, the corresponding social welfare is equal to 1.67118 and $\bar{p}=1.58507$.

\subsection{Gains from Trade}

We have demonstrated that moving from autarky to free trade without compensating those whose welfare is reduced by such a move can be welfare reducing. Of course, we expect that if trade is accompanied by the appropriate income redistribution then it will be not only welfare enhancing but also Pareto-improving. We show that this is true for the case of CobbDouglas preferences.

Proposition 9 Suppose that preferences are described by the utility function $U(X, Y)=A X^{\gamma} Y^{\delta}$. Then trade always Pareto dominates autarky if it is accompanied by the appropriate income redistribution.

Proof. See the Appendix.

\section{Trade and Political Economy Equilibrium}

In the previous section we showed that welfare results depend critically on whether or not there is redistribution of income to compensate those agents who suffer losses under free trade. In this section, we demonstrate that such policies might be ruled out in a political economy equilibrium. In addition, we are going to show that it is possible that the majority might vote for trade without redistribution even when trade reduces aggregate welfare. We adopt a very simple political economy model and assume that majority voting decides (a) the choice between autarky and trade, and (b) any redistribution policies. ${ }^{10}$ Our work follows the median-voter approach to trade policy that was first employed by Mayer (1984) in his classic work on endogenous tariff formation.

We completely characterize the political economy equilibria for the case of diminishing marginal utility of income $(\theta<1)^{11}$ and prices in the interval

\footnotetext{
${ }^{10}$ Implicitly, in the text we have assumed that when both votes are available they take place simultaneously. However, the results remain the same in the case of as sequential voting procedure.

${ }^{11}$ Similar results can be obtained when $\theta \geqslant 1$.
} 
$(1,2)$. Our first proposition characterizes equilibria when redistribution is not on the political agenda while the second proposition characterizes the equilibria when both options are available. Let $h^{m}$ denote the human capital endowment of the median voter; i.e. $F_{A}\left(h^{m}\right)=0.5$.

Remember that when the marginal utility of income is diminishing if $p<p_{T}<p_{A}$ uncompensated trade reduces social welfare. We need to consider three cases. The first case is when $1<p_{T}<p<p_{A}<2$. We know that the welfare of all those agents with human capital endowments such that $h>p_{A}$ is higher under trade and the welfare of all agents with human capital endowments such that $h<p_{T}$ is lower under trade. Since utility is weakly monotonic in endowments it implies that for those agents, with human capital endowments such that $p_{T}<h<p_{A}$ there exists a threshold level of endowment $h_{1}$ such that the welfare of all agents with human capital endowments such that $p_{T}<h<h_{1}$ is lower under trade and the welfare of all agents with human capital endowments such that $h_{1}<h<p_{A}$ is higher under trade.

The second case is when $1<p<p_{T}<p_{A}<2$. As in the previous case, there exists a threshold level of endowment $h_{2}$ such that the welfare of all agents with human capital endowments such that $p_{T}<h<h_{2}$ is lower under trade and the welfare of all agents with human capital endowments such that $h_{2}<h<p_{A}$ is higher under trade.

The last case is when $1<p<p_{A}<p_{T}<2$. Now, the welfare of all those agents with human capital endowments such that $h<p_{A}$ is higher under trade and the welfare of all agents with human capital endowments such that $h>p_{T}$ is lower under trade. Using a similar argument as above we can show that there exists a threshold level of income $h_{3}$ such that the welfare of all agents with human capital endowments such that $p_{A}<h<$ $h_{3}$ is higher under trade and the welfare of all agents with human capital endowments such that $h_{3}<h<p_{T}$ is lower under trade.

When the political agenda does not include the option of redistribution we have the following proposition:

Proposition 10 Characterization of Politico-Economic Equilibria without redistribution for $\theta<1$.

Let $1<p_{T}<\underline{p}$

If $h_{1}>h^{m}$ then Autarky

If $h_{1}<h^{m}$ then Trade (Social welfare increases)

Let $p<p_{T}<p_{A}$

If $h_{2}>h^{m}$ then Autarky

If $h_{2}<h^{m}$ then Trade (Social welfare decreases) 


$$
\begin{aligned}
& \text { Let } p_{A}<p_{T}<2 \\
& \text { If } h_{3}>h^{m} \text { then Trade (Social welfare increases) } \\
& \text { If } h_{3}<h^{m} \text { then Autarky }
\end{aligned}
$$

In contrast, when the option of redistribution is included in the political agenda we get:

Proposition 11 Characterization of Politico-Economic Equilibria with redistribution for $\theta<1$.

Let $1<p_{T}<p$

If $h_{1}>h^{m}$ then Trade with Redistribution

If $h_{1}<h^{m}$ then Trade without Redistribution (Social welfare increases)

Let $p<p_{T}<p_{A}$

If $h_{2}>\bar{h}^{m}$ then Trade with Redistribution

If $h_{2}<h^{m}$ then Trade without Redistribution (Social welfare decreases)

Let $p_{A}<p_{T}<2$

If $h_{3}>h^{m}$ then Trade without Redistribution (Social welfare increases)

If $h_{3}<h^{m}$ then Trade with Redistribution

The results follow directly from the fact that when the majority of voters are better off under trade then the outcome of the first vote will be 'Trade' and when the second vote is available the outcome will be 'Trade without Redistribution'. In contrast, when the majority of voters are better off under autarky then the outcome of the first vote will be 'Autarky' and when the second vote is available the outcome will be 'Trade with Redistribution'.

In other words, the availability of redistribution always leads to openness, however, not necessarily to higher welfare. ${ }^{12}$ It is useful at this point to compare our results with those in Mayer (1984) that were derived within a Heckscher-Ohlin Framework. Mayer (1984) predicts that an increase in inequality (where agents differ in their endowments of physical capital) that keeps aggregate endowments the same will raise trade barriers in capitalabundant economies and will lower them in capital-scarce economies. The intuition behind this result is that capital-abundant countries export the capital intensive good. As inequality increases the mass of agents that benefits from trade decreases and thus trade barriers are raised. The reverse rationale holds for capital-scarce economies.

In contrast, in our model it is the distribution of human capital that determines the pattern of trade. A change in inequality in our model has

\footnotetext{
${ }^{12}$ Mayer (1984) resticted his analysis to the case of a constant marginal utility of income and thus in his model uncompensated trade is always welfare increasing.
} 
uncertain effects on the pattern of trade and therefore its effect on voting patterns is not straightforward. But it is still the case that if the number of agents that benefit from trade decreases then trade barriers might be raised.

\section{Conclusion}

In this paper, we have assumed that the distribution of human capital is exogenous. One obvious extension would be to allow for endogenous accumulation of skills. This can be accomplished by considering an economy in which 2-period lived agents spend their first period of their lives investing in skill accumulation while during the second period produce, trade and consume. In such a model, the agents' investment in skills will depend on their expectations about both government policies and the trade regime. Because of the associated costs with skill accumulation, underemployment of human capital becomes a much more serious issue.

There are two types of government policies that would be worthwhile to consider; namely redistribution policies and educational subsidies. There is a growing literature that examines issues related to the relationship between skill accumulation and income inequality but the majority of the work in this area has ignored government policies. Two exceptions are Deardoff (1997) and Janeba (2000). However both papers focus on the optimality of government policies ignoring their potential implementation in systems where decisions are not taken by a social planner but rely on a majority rule.

Another possible extension is to consider the problem that governments face when they decide how to allocate a fixed budget for investments in human capital accumulation. In this case, government policies determine the distribution of human capital which in turn determines the patterns of trade and post-trade income distribution.

A third extension would be to apply our model to immigration issues. As it stands our model cannot explain immigration because we obtain factor price equalization. ${ }^{13}$ However, by adding a third factor, say physical capital, that is complimentary to human capital factor price equalization might fail. Our analysis suggests that immigration or emigration of agents will affect both welfare and income distribution.

\footnotetext{
${ }^{13}$ In Ishikawa (1996) immigration is possible because national economies of scale with respect to human capital imply that an individual's efficiency units change with migration and factor price equalization obtains only in terms of efficiency units.
} 


\section{APPENDIX}

\subsection{Proof of Proposition 7}

Using the demand functions that we derived in example 1, we find that we can write the indirect utility function $V$ of an agent with income $h$ who trades at price $p$ as

$$
V=c \frac{h^{\gamma+\delta}}{p^{\delta}}
$$

where $c=A\left(\frac{\gamma}{\gamma+\delta}\right)^{\gamma}\left(\frac{\delta}{\gamma+\delta}\right)^{\delta}$. Notice that the income of an agent who produces the primary commodity is equal to $p$.

Then, using (2), social welfare is given by:

$$
p^{\gamma} \int_{1}^{p} f(h) d h+p^{-\delta} \int_{p}^{h_{M A X}} h^{\gamma+\delta} f(h) d h
$$

The f.o.c. condition for a minimum is given by:

$$
p^{-1}\left(\gamma p^{\gamma} F(p)-\delta p^{-\delta} \int_{p}^{h_{M A X}} h^{\gamma+\delta} f(h) d h\right)=0
$$

Notice that the s.o.c. is also satisfied. Rearranging the above expression we find that if the social welfare minimizing price is given by the solution of the following equation::

$$
p^{\gamma+\delta}=\frac{\delta}{\gamma} \frac{\int_{p^{a}}^{h_{M A X}} h^{\gamma+\delta} f(h) d h}{F(p)}
$$

The proof is completed by adding the observation that unless $\gamma+\delta=1$ the solution of the above equation will not be equal to $p^{a}$.

\subsection{Proof of Proposition 8}

Let $\theta=\gamma+\delta$ and $k=\frac{\delta}{\gamma}$. From proposition (7) we know that the price that minimizes social welfare is given by the solution to the following equation

$$
p^{\theta}=k \frac{\int_{p}^{2} h^{\theta} d h}{p-1}
$$

In order to prove the proposition we need to show that this price increases with $\theta$, i.e. the marginal utility of income. The reason that this step is 
sufficient follows from (a) proposition 7 , where we have shown that when $\theta=1$ the minimum is attained at the autarky price, and (b) the continuity of the social welfare function with respect to $p$. After solving the integral and rearranging the above expression we get

$$
p^{1+\theta}\left(1+\frac{k}{1+\theta}\right)-p^{\theta}=k \frac{1}{1+\theta} 2^{\theta+1}
$$

The left-hand side of (A1), denoted by $L$, is strictly increasing in $p$ while the right-hand side, denoted by $R$, is independent of $p$. Then to complete the proof we need to show that $\frac{d L}{d \theta}<\frac{d R}{d \theta}$. Now,

$$
\frac{d L}{d \theta}=p^{\theta+1}\left(1+\frac{k}{1+\theta}\right) \log p-p^{\theta+1} \frac{k}{(1+\theta)^{2}}-p^{\theta} \log p
$$

and

$$
\frac{d R}{d \theta}=-\frac{k}{(1+\theta)^{2}} 2^{\theta+1}+\frac{k}{1+\theta} 2^{\theta+1} \log 2
$$

thus

$$
\begin{aligned}
\frac{d R}{d \theta}-\frac{d L}{d \theta}= & \frac{k}{1+\theta}\left(2^{\theta+1} \log 2-p^{\theta+1} \log p\right)-\frac{k}{(1+\theta)^{2}}\left(2^{\theta+1}-p^{\theta+1}\right)(\mathrm{A} 2) \\
& p^{\theta}(p-1) \log p
\end{aligned}
$$

From (A1) we find that

$$
\frac{k}{1+\theta}=\frac{p^{\theta}(p-1)}{2^{\theta+1}-p^{\theta+1}}
$$

We can substitute this expression in (A2) to get

$$
\begin{aligned}
\frac{d R}{d \theta}-\frac{d L}{d \theta}= & \frac{p^{\theta}(p-1)}{2^{\theta+1}-p^{\theta+1}}\left(2^{\theta+1} \log 2-p^{\theta+1} \log p\right)-\frac{1}{1+\theta} p^{\theta}(p-1)- \\
& p^{\theta}(p-1) \log p \\
= & \frac{2^{\theta+1} \log 2-p^{\theta+1} \log p}{2^{\theta+1}-p^{\theta+1}}-\frac{1}{1+\theta}-\log p \\
= & (1+\theta) 2^{\theta+1}(\log 2-\log p)-\left(2^{\theta+1}-p^{\theta+1}\right)
\end{aligned}
$$

But this last expression is monotonically decreasing in $p$ for $1<p<2$ and it is equal to 0 for $p=2$ which completes the proof. 


\subsection{Proof of Proposition 9}

Let $p_{A}$ and $h_{A}$ denote the equilibrium price and income under autarky and $p_{T}$ and $h_{T}$ the equilibrium price and income under trade. Then we can write the indirect utility function under autarky as

$$
V_{A}=\frac{h_{A}^{\gamma+\delta}}{p_{A}^{\delta}}
$$

and the indirect utility function under trade as:

$$
V_{T}=\frac{h_{T}^{\gamma+\delta}}{p_{T}^{\delta}}
$$

Since preferences are homothetic a change in income at any given price level will not affect the shares of income spent on each good. Suppose that after trade we adjust each agent's income so that their post-adjustment indirect utility is equal to their indirect utility under autarky. Let $\tau\left(h_{T}\right)$ denote the tax (subsidy if negative) imposed on an agent whose post-trade income is equal to $h$. By definition the tax (subsidy) must satisfy the following equality:

$$
\frac{\left(h_{T}-\tau\left(h_{T}\right)\right)^{\gamma+\delta}}{p_{T}^{\delta}}=\frac{h_{A}^{\gamma+\delta}}{p_{A}^{\delta}}, \forall h
$$

Rearranging the above expression we find that the tax (subsidy) must satisfy

$$
\tau\left(h_{T}\right)=h_{T}-h_{A}\left(\frac{p_{T}}{p_{A}}\right)^{\frac{\delta}{\gamma+\delta}}
$$

In order to prove the proposition we need to show that

$$
\int_{1}^{h_{M A X}} \tau\left(h_{T}\right) f(h) d h>0
$$

That is, aggregate tax revenues must be higher than aggregate subsidy expenditures which implies that the tax revenues raised from those agents whose welfare improves under trade is higher than the total amount of subsidies offered to those agents whose welfare deteriorates. Substituting (6) in 
the left-hand side of (7) we get:

$$
\begin{aligned}
& \int_{1}^{p_{T}}\left(p_{T}-p_{A}\left(\frac{p_{T}}{p_{A}}\right)^{\frac{\delta}{\gamma+\delta}}\right) f(h) d h+\int_{p_{T}}^{p_{A}}\left(h-p_{A}\left(\frac{p_{T}}{p_{A}}\right)^{\frac{\delta}{\gamma+\delta}}\right) f(h) d h \\
& +\int_{p_{A}}^{h_{M A X}}\left(h-h\left(\frac{p_{T}}{p_{A}}\right)^{\frac{\delta}{\gamma+\delta}}\right) f(h) d h \\
= & p_{T} F\left(p_{T}\right)+\int_{p_{T}}^{h_{M A X}} h f(h) d h-p_{A}\left(\frac{p_{T}}{p_{A}}\right)^{\frac{\delta}{\gamma+\delta}} F\left(p_{A}\right) \\
& -\left(\frac{p_{T}}{p_{A}}\right)^{\frac{\delta}{\gamma+\delta}} \int_{p_{A}}^{h_{M A X}} h f(h) d h
\end{aligned}
$$

Notice that this expression is the same for $p_{T}>p_{A}$ and $p_{T}<p_{A}$. The proof will be complete if we can show that the above function is minimized when $p_{T}=p_{A}$. After differentiating the above function with respect to $p_{T}$, setting $p_{T}$ equal to $p_{A}$ in the derivative and solving the final expression for $p_{A}$ we find that the solution for $p_{A}$ is given by equation (1) which gives the solution for the autarky price. Then the above function achieves a global optimum when $p_{T}$ is equal to the autarky price. It is easy to verify that the S.O.C. also holds. 


\section{References}

[1] Brander J., 1981, "Intra-industry Trade in Identical Commodities," Journal of International Economics 11, 1-14.

[2] Davidson C. and S. Matusz, 2002, "Trade Liberalization and Compensation," GEP Research Parer Series 2002/10..

[3] Davidson C. and S. Matusz, 2004, International Trade and Labor Markets: Theory, Evidence and Policy Implications, W.E. Upjohn Institute, Kalamazoo.

[4] Davidson C., S. Matusz and D. Nelson, 2004, "Can Compensation Save Free Trade," mimeo.

[5] Davis D., 1995, "Intra-industry Trade: A Heckscher-Ohlin-Ricardo Approach," Journal of International Economics 39, 201-26.

[6] Deardoff A., 1997, "International Externalities in the Use of Domestic Policies to Redistribute Income," Discussion Paper No. 405, University of Michigan.

[7] Feenstra R. and G. Hanson, 1996, "Foreign Investment, Outsourcing, and Relative Wages," in R. Feenstra and G. Grossman (eds.) The Political Economy of Trade Policy: Papers in Honor of Jagdish Bhagwati, MIT Press, Cambridge.

[8] Feenstra R. and G. Hanson, 2001, "Global Production Sharing and Rising Inequality: A Survey of Trade and Wages," NBER Working Paper 8372.

[9] Grossman G., 2004, "The Distribution of Talent and the Pattern and Consequences of International Trade," Journal of Political Economy 112, 209-39.

[10] Grossman G. and G. Maggi, 2000, "Diversity and Trade," American Economic Review 90, 1255-75.

[11] Ishikawa J., 1996, "Scale Economies in Factor Supplies, International Trade, and Migration," Canadian Journal of Economics 29, 573-94.

[12] Janeba E., 2000, "Trade, Income Inequality, and Government Policies: Redistribution of Income or Education Subsidies?" NBER Working Paper 7485 . 
[13] Krugman P., 1979, "Increasing Returns, Monopolistic Competition, and International Trade," Journal of International Economics 9, 46979 .

[14] Mayer W., 1984, "Endogenous Tariff Formation," American Economic Review 74, 970-85.

[15] Zhu S. and D. Trefler, 2005, "Trade and Inequality in Developing countries: A General Equilibrium Analysis," Journal of International Economics $65,21-48$. 


\title{
CESifo Working Paper Series
}

\author{
(for full list see www.cesifo-group.de)
}

1409 Christian Gollier, Some Aspects of the Economics of Catastrophe Risk Insurance, February 2005

1410 Gebhard Kirchgässner, The Weak Rationality Principle in Economics, February 2005

1411 Carlos José Fonseca Marinheiro, Has the Stability and Growth Pact Stabilised? Evidence from a Panel of 12 European Countries and Some Implications for the Reform of the Pact, February 2005

1412 Petter Osmundsen, Frank Asche, Bård Misund and Klaus Mohn, Valuation of International Oil Companies -The RoACE Era, February 2005

1413 Gil S. Epstein and Shmuel Nitzan, Lobbying and Compromise, February 2005

1414 Marcel F. M. Canoy, Jan C. van Ours and Frederick van der Ploeg, The Economics of Books, February 2005

1415 Eric A. Hanushek and Ludger Wößmann, Does Educational Tracking Affect Performance and Inequality? Differences-in-Differences Evidence across Countries, February 2005

1416 George Kapetanios and M. Hashem Pesaran, Alternative Approaches to Estimation and Inference in Large Multifactor Panels: Small Sample Results with an Application to Modelling of Asset Returns, February 2005

1417 Samuel Mühlemann, Jürg Schweri, Rainer Winkelmann and Stefan C. Wolter, A Structural Model of Demand for Apprentices. February 2005

1418 Giorgio Brunello and Lorenzo Rocco, Educational Standards in Private and Public Schools, February 2005

1419 Alex Bryson, Lorenzo Cappellari and Claudio Lucifora, Why so Unhappy? The Effects of Unionisation on Job Satisfaction, March 2005

1420 Annalisa Luporini, Relative Performance Evaluation in a Multi-Plant Firm, March 2005

1421 Giorgio Bellettini and Carlotta Berti Ceroni, When the Union Hurts the Workers: A Positive Analysis of Immigration Policy, March 2005

1422 Pieter Gautier, Michael Svarer and Coen Teulings, Marriage and the City, March 2005

1423 Ingrid Ott and Stephen J. Turnovsky, Excludable and Non-Excludable Public Inputs: Consequences for Economic Growth, March 2005

1424 Frederick van der Ploeg, Back to Keynes?, March 2005 
1425 Stephane Dees, Filippo di Mauro, M. Hashem Pesaran and L. Vanessa Smith, Exploring the International Linkages of the Euro Area: a Global VAR Analysis, March 2005

1426 Hans Pitlik, Friedrich Schneider and Harald Strotmann, Legislative Malapportionment and the Politicization of Germany’s Intergovernmental Transfer System, March 2005

1427 Konstantinos Angelopoulos and Apostolis Philippopoulos, The Role of Government in Anti-Social Redistributive Activities, March 2005

1428 Ansgar Belke and Daniel Gros, Asymmetries in the Trans-Atlantic Monetary Policy Relationship: Does the ECB follow the Fed?, March 2005

1429 Sören Blomquist and Luca Micheletto, Optimal Redistributive Taxation when Government’s and Agents’ Preferences Differ, March 2005

1430 Olof Åslund and Peter Fredriksson, Ethnic Enclaves and Welfare Cultures - QuasiExperimental Evidence, March 2005

1431 Paul De Grauwe, Roberto Dieci and Marianna Grimaldi, Fundamental and NonFundamental Equilibria in the Foreign Exchange Market. A Behavioural Finance Framework, March 2005

1432 Peter Egger, Stefan Gruber, Mario Larch and Michael Pfaffermayr, Knowledge-Capital Meets New Economic Geography, March 2005

1433 George Economides and Apostolis Philippopoulos, Should Green Governments Give Priority to Environmental Policies over Growth-Enhancing Policies?, March 2005

1434 George W. Evans and Seppo Honkapohja, An Interview with Thomas J. Sargent, March 2005

1435 Helge Berger and Volker Nitsch, Zooming Out: The Trade Effect of the Euro in Historical Perspective, March 2005

1436 Marc-Andreas Muendler, Rational Information Choice in Financial Market Equilibrium, March 2005

1437 Martin Kolmar and Volker Meier, Intra-Generational Externalities and InterGenerational Transfers, March 2005

1438 M. Hashem Pesaran and Takashi Yamagata, Testing Slope Homogeneity in Large Panels, March 2005

1439 Gjermund Nese and Odd Rune Straume, Industry Concentration and Strategic Trade Policy in Successive Oligopoly, April 2005

1440 Tomer Blumkin and Efraim Sadka, A Case for Taxing Education, April 2005

1441 John Whalley, Globalization and Values, April 2005 
1442 Denise L. Mauzerall, Babar Sultan, Namsoug Kim and David F. Bradford, Charging $\mathrm{NO}_{x}$ Emitters for Health Damages: An Exploratory Analysis, April 2005

1443 Britta Hamburg, Mathias Hoffmann and Joachim Keller, Consumption, Wealth and Business Cycles in Germany, April 2005

1444 Kohei Daido and Hideshi Itoh, The Pygmalion Effect: An Agency Model with Reference Dependent Preferences, April 2005

1445 John Whalley, Rationality, Irrationality and Economic Cognition, April 2005

1446 Henning Bohn, The Sustainability of Fiscal Policy in the United States, April 2005

1447 Torben M. Andersen, Is there a Role for an Active Fiscal Stabilization Policy? April 2005

1448 Hans Gersbach and Hans Haller, Bargaining Power and Equilibrium Consumption, April 2005

1449 Jerome L. Stein, The Transition Economies: A NATREX Evaluation of Research, April 2005

1450 Raymond Riezman, John Whalley and Shunming Zhang, Metrics Capturing the Degree to which Individual Economies are Globalized, April 2005

1451 Romain Ranciere, Aaron Tornell and Frank Westermann, Systemic Crises and Growth, April 2005

1452 Plutarchos Sakellaris and Focco W. Vijselaar, Capital Quality Improvement and the Sources of Growth in the Euro Area, April 2005

1453 Kevin Milligan and Michael Smart, Regional Grants as Pork Barrel Politics, April 2005

1454 Panu Poutvaara and Andreas Wagener, To Draft or not to Draft? Efficiency, Generational Incidence, and Political Economy of Military Conscription, April 2005

1455 Maurice Kugler and Hillel Rapoport, Skilled Emigration, Business Networks and Foreign Direct Investment, April 2005

1456 Yin-Wong Cheung and Eiji Fujii, Cross-Country Relative Price Volatility: Effects of Market Structure, April 2005

1457 Margarita Katsimi and Thomas Moutos, Inequality and Relative Reliance on Tariffs: Theory and Evidence, April 2005

1458 Monika Bütler, Olivia Huguenin and Federica Teppa, Why Forcing People to Save for Retirement may Backfire, April 2005

1459 Jos Jansen, The Effects of Disclosure Regulation of an Innovative Firm, April 2005 
1460 Helge Bennmarker, Kenneth Carling and Bertil Holmlund, Do Benefit Hikes Damage Job Finding? Evidence from Swedish Unemployment Insurance Reforms, May 2005

1461 Steffen Huck, Kai A. Konrad and Wieland Müller, Merger without Cost Advantages, May 2005

1462 Louis Eeckhoudt and Harris Schlesinger, Putting Risk in its Proper Place, May 2005

1463 Hui Huang, John Whalley and Shunming Zhang, Trade Liberalization in a Joint Spatial Inter-Temporal Trade Model, May 2005

1464 Mikael Priks, Optimal Rent Extraction in Pre-Industrial England and France - Default Risk and Monitoring Costs, May 2005

1465 François Ortalo-Magné and Sven Rady, Heterogeneity within Communities: A Stochastic Model with Tenure Choice, May 2005

1466 Jukka Pirttilä and Sanna Tenhunen, Pawns and Queens Revisited: Public Provision of Private Goods when Individuals make Mistakes, May 2005

1467 Ernst Fehr, Susanne Kremhelmer and Klaus M. Schmidt, Fairness and the Optimal Allocation of Ownership Rights, May 2005

1468 Bruno S. Frey, Knight Fever - Towards an Economics of Awards, May 2005

1469 Torberg Falch and Marte Rønning, The Influence of Student Achievement on Teacher Turnover, May 2005

1470 John Komlos and Peter Salamon, The Poverty of Growth with Interdependent Utility Functions, May 2005

1471 Hui Huang, Yi Wang, Yiming Wang, John Whalley and Shunming Zhang, A Trade Model with an Optimal Exchange Rate Motivated by Current Discussion of a Chinese Renminbi Float, May 2005

1472 Helge Holden, Lars Holden and Steinar Holden, Contract Adjustment under Uncertainty, May 2005

1473 Kai A. Konrad, Silent Interests and All-Pay Auctions, May 2005

1474 Ingo Vogelsang, Electricity Transmission Pricing and Performance-Based Regulation, May 2005

1475 Spiros Bougheas and Raymond Riezman, Trade and the Distribution of Human Capital, June 2005 